\title{
Central venous catheter use in severe malaria: time to reconsider the World Health Organization guidelines?
}

\author{
Josh Hanson 1,2*, Sophia WK Lam², Sanjib Mohanty ${ }^{3}$, Shamshul Alam4, Md Mahtab Uddin Hasan ${ }^{5}$, Sue J Lee ${ }^{2}$, \\ Marcus J Schultz ${ }^{6}$, Prakaykaew Charunwatthana ${ }^{2}$, Sophie Cohen ${ }^{7}$, Ashraf Kabir ${ }^{8}$, Saroj Mishra ${ }^{3}$, Nicholas PJ Day ${ }^{2,9}$, \\ Nicholas J White ${ }^{2,9}$ and Arjen M Dondorp ${ }^{2,9}$
}

\begin{abstract}
Background: To optimize the fluid status of adult patients with severe malaria, World Health Organization (WHO) guidelines recommend the insertion of a central venous catheter (CVC) and a target central venous pressure (CVP) of $0-5 \mathrm{cmH}_{2} \mathrm{O}$. However there are few data from clinical trials to support this recommendation.

Methods: Twenty-eight adult Indian and Bangladeshi patients admitted to the intensive care unit with severe falciparum malaria were enrolled in the study. All patients had a CVC inserted and had regular CVP measurements recorded. The CVP measurements were compared with markers of disease severity, clinical endpoints and volumetric measures derived from transpulmonary thermodilution.

Results: There was no correlation between the admission CVP and patient outcome ( $p=0.67)$ or disease severity $(p=0.33)$. There was no correlation between the baseline CVP and the concomitant extravascular lung water $(p=0.62)$, global end diastolic volume $(p=0.88)$ or cardiac index $(p=0.44)$. There was no correlation between the baseline CVP and the likelihood of a patient being fluid responsive $(p=0.37)$. On the occasions when the CVP was in the WHO target range patients were usually hypovolaemic and often had pulmonary oedema by volumetric measures. Seven of 28 patients suffered a complication of the CVC insertion, although none were fatal.

Conclusion: The WHO recommendation for the routine insertion of a CVC, and the maintenance of a CVP of 0-5 $\mathrm{CmH}_{2} \mathrm{O}$ in adults with severe malaria, should be reconsidered.
\end{abstract}

\section{Background}

The introduction of artemisinin-based therapy has revolutionized the care of patients with malaria. However, even with intravenous artesunate, the mortality rate of adults with severe malaria in many Asian hospitals remains over 15\%; the majority dying during the first 48 hours of their hospitalization [1].

Guidelines for the initial management of patients with sepsis make a series of recommendations based on data collected in multicentre trials [2]; adherence to these guidelines has been shown to improve patient outcomes $[3,4]$. In contrast, there has been a paucity of clinical trials of patients with malaria and so treatment

\footnotetext{
* Correspondence: drjoshhanson@gmail.com

'Department of Medicine, Cairns Base Hospital, Queensland, Australia Full list of author information is available at the end of the article
}

recommendations for early supportive care are still based largely on expert opinion [5,6].

The management of a patient's fluid status is one of the most fundamental aspects of supportive care. However, clinical assessment of the degree of hypovolaemia is challenging [7] and there is frequently great interobserver variability [8]. To overcome the limitations of physical examination, critically ill patients will commonly have a catheter inserted into a large central vein to measure the central venous pressure (CVP). CVP is an objective measure of the filling pressure of the heart and has been used in the critical care setting to guide the administration of replacement fluids. In the current Surviving Sepsis Guidelines, fluid resuscitation to achieve a CVP of 8-12 $\mathrm{mmHg}$ is one of the key recommendations [2]. Optimizing the fluid status of patients

\section{Biomed Central}


with severe malaria also has appeal as this group has a reduced effective circulating volume [9-11] and lactic acidosis and renal impairment - both exacerbated by reduced tissue perfusion - are important contributors to mortality [12]. Fluid resuscitation has the added advantage of being simple and inexpensive to implement.

Yet in adults with severe malaria, there is also an increase in pulmonary capillary permeability and pulmonary oedema is an important cause of death [13]; hence the old malariologist's adage: "run them dry". This is recognized in the WHO guidelines where experts recommend the use of a central venous catheter (CVC) and a target central venous pressure (CVP) of $0-5$ $\mathrm{cmH}_{2} \mathrm{O}$ to address the "very thin dividing line between overhydration, which may produce pulmonary oedema, and underhydration contributing to shock and worsening acidosis and renal impairment" [5].

However, the insertion of a CVC may be associated with mechanical, haemorrhagic and infectious complications [14]. Patients with severe malaria may have thrombocytopaenia and coagulopathy increasing the risk of haemorrhage. The vast majority of patients with severe malaria will have to be managed in a resource-poor environment and in this setting a CVC is relatively costly. Furthermore there has recently been a move away from reliance on pressure-based measures of preload given the limited correlation between such measures and true volume status $[15,16]$.

Thus, there is a concern that an expensive intervention is being recommended which could increase risks for the patient without providing useful guidance for the clinician. As part of a study examining fluid resuscitation of adults with severe malaria we aimed to determine the utility of CVP in the management of this group of patients.

\section{Methods \\ Study}

The primary study, of which this analysis is a sub-study, examined the response of adult patients with severe Plasmodium falciparum malaria to fluid loading. Ethical approval for the study was obtained from the Bangladeshi Medical Research Council, the Institutional Ethical Board of Ispat General Hospital, and the Oxford Tropical Medicine Research Ethical Committee. There were regular scheduled reviews of the study by independent local safety committees. Patients were enrolled only after written informed consent was obtained from an accompanying relative via a local translator.

\section{Patients}

Patients were recruited at Chittagong Medical College Hospital in Bangladesh and Ispat General Hospital in Rourkela, India in 2008. At both sites malaria is endemic with seasonal peaks in transmission. Patients were defined as having malaria if asexual forms of $P$. falciparum were present on blood film or, if expert microscopy was not immediately available, an immunochromatographic test (Paracheck Pf, Orchid Biomedical Systems, India) was positive. In these cases falciparum malaria was later confirmed by microscopic examination of a simultaneously collected slide. As invasive haemodynamic monitoring was being employed, only the sickest patients were enrolled. The prospectively defined severity criteria were: a peripheral venous base deficit of $>6 \mathrm{mmol} / \mathrm{L}$, a blood urea nitrogen $>60 \mathrm{mg} / \mathrm{dL}$ $(21.4 \mathrm{mmol} / \mathrm{L})$ or pulmonary oedema (defined as oxygen saturation $<90 \%$ on room air with bi-basal crepitations on respiratory examination). These inclusion criteria were a modification of the WHO criteria for severe malaria and reflected the potential for iatrogenic harm from insertion of the CVC and arterial catheter. Patients were excluded if they were $<16$ years old or if they had already received artesunate for $>24$ hours prior to enrolment.

\section{Treatment protocol}

All patients were admitted to the intensive care unit (ICU). A detailed history and physical examination was performed on all patients who were treated with intravenous artesunate and standard supportive care as per current treatment guidelines [5]. Jugular venous pressure (JVP) was determined by inspecting the internal jugular vein (IJV) or the external jugular vein if the IJV was not seen. The JVP was classified as not visible, just visible, normal, or elevated. A 7 French 20 centimetre triple lumen central venous catheter (CVC) (Arrow, North Carolina, USA) was placed by an clinician experienced in insertion of central venous catheters using the Seldinger technique in either the subclavian vein (SCV) or the IJV; the SCV was preferred unless the patient had respiratory compromise. A chest $\mathrm{x}$-ray was performed to confirm the correct positioning of the CVC and exclude complications of its insertion. CVP was then recorded using a manometer connected to the patient and a flask of saline via a three-way tap, the level of the right atrium was designated as the zero point. Nurses in both ICUs were unfamiliar with CVCs and so received training during the course of the study. The CVC insertion site was dressed daily with $2 \%$ chlorhexidine and nonocclusive sterile gauze. Further haemodynamic measurements were made using transpulmonary thermodilution and arterial pulse contour analysis (PiCCO plus ${ }^{\circledR}$, Pulsion, Germany) using the CVC and a 5 French thermistor-tipped arterial catheter (Pulsiocath, Pulsion, Germany) inserted into the femoral artery. The physiological basis for measurement of haemodynamic variables using the PiCCO system has been published in 
detail elsewhere $[17,18]$. Briefly, chilled saline $\left(<8^{\circ}\right.$ Celsius) was injected into the superior vena cava via the CVC and the thermistor at the tip of the femoral artery catheter measured the downstream temperature change. Cardiac output was calculated by analysis of the thermodilution curve using a modified Stewart-Hamilton algorithm. All volumetric parameters were obtained by advanced analysis of the thermodilution curve. These parameters included global end diastolic volume (GEDI) - a measure of volume status - and extra vascular lung water (EVLW). The patient's height was used to calculate the ideal body weight for the calculation of indexed values.

Patients were resuscitated with isotonic saline using published PiCCO measurement based, CVP independent, resuscitation algorithms $[19,20]$. Blood was transfused if the haemoglobin fell below $5 \mathrm{~g} / \mathrm{dL}$. Repeat Respiratory support, renal replacement therapy (RRT) and inotropic support were initiated based on the judgement of the clinicians. Disease severity was determined using the "CAM" score [12].

\section{Laboratory}

Thick and thin blood films for parasite quantification, a full blood count and plasma biochemistry were collected on admission. On admission and during the study measures of biochemistry and haemoglobin were determined by a handheld automated analyser (iStat, Abbott Laboratories, New Jersey, USA). Sequential blood films to confirm parasitological response were collected. Blood cultures were collected in patients in whom concomitant bacterial infection was felt to be possible. Other investigations were initiated according to the clinical judgement of the attending staff.

\section{Statistics}

Data were collected and entered into a de-identified database and analysed using statistical software (Version 10, StataCorp). Correlation coefficients were determined using Spearman's method. Differences between groups were analysed using the Kruskal-Wallis and Chi-squared tests.

\section{Results}

\section{Patient characteristics}

Twenty-eight patients were included in this study, five (17.8\%) of whom died. Their baseline characteristics are recorded in Table 1. All the patients were felt to have their clinical presentation explained solely by severe falciparum malaria. In the course of their admissions, 11 received respiratory assistance (eight endotracheal intubation and mechanical ventilation, three continuous positive airways pressure ventilation by facemask) and six received RRT (three peritoneal dialysis, three
Table 1 Baseline characteristics of the patients

\begin{tabular}{|c|c|c|}
\hline Variable & Median value & Range \\
\hline Age & 36 years & $(17-66)$ \\
\hline Sex & 19/28 (68\%) male & - \\
\hline Heart rate & $\begin{array}{l}102 \text { beats per } \\
\text { minute }\end{array}$ & $78-126$ \\
\hline Mean arterial pressure & $84 \mathrm{~mm} \mathrm{Hg}$ & $58-110$ \\
\hline Glasgow Coma Score & 13 & $4-15$ \\
\hline Oxygen saturation & $98 \%$ & $86-100$ \\
\hline Haemoglobin & $10.4 \mathrm{~g} / \mathrm{dL}$ & $5.1-14.3$ \\
\hline White cell count & $8.0 \times 10^{9} / \mathrm{L}$ & $3-21.4$ \\
\hline Platelets & $26 \times 10^{9} / \mathrm{L}$ & $8-244$ \\
\hline Parasite count & 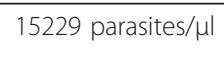 & $\begin{array}{c}38- \\
2411897\end{array}$ \\
\hline Sodium & $134 \mathrm{mmol} / \mathrm{L}$ & $120-150$ \\
\hline Potassium & $3.9 \mathrm{mmol} / \mathrm{L}$ & $2.7-5.1$ \\
\hline Blood urea nitrogen & $15 \mathrm{mmol} / \mathrm{L}$ & $2-50^{*}$ \\
\hline Creatinine & $172 \mu \mathrm{mol} / \mathrm{L}$ & $70-862$ \\
\hline Bicarbonate & $16.9 \mathrm{mmol} / \mathrm{L}$ & $6.6-22$ \\
\hline Lactate & $3.1 \mathrm{mmol} / \mathrm{L}$ & $0.46-12.8$ \\
\hline Base deficit & $-9 \mathrm{mmol} / \mathrm{L}$ & $-4--23$ \\
\hline Central Venous Pressure & $5.25 \mathrm{~cm} \mathrm{H}_{2} \mathrm{O}$ & -7 to 13 \\
\hline Global End Diastolic Index & $481 \mathrm{ml} / \mathrm{m}^{2}$ & $346-675$ \\
\hline Extra Vascular Lung Water & $8 \mathrm{ml} / \mathrm{Kg}$ & 5-14 \\
\hline Cardiac Index & $3.1 \mathrm{~L} / \mathrm{min} / \mathrm{m}^{2}$ & $2.27-5.24$ \\
\hline Oxygen delivery $\left(\mathrm{DO}_{2}\right)$ & $420 \mathrm{ml} / \mathrm{min} / \mathrm{m}^{2}$ & $253-603$ \\
\hline $\begin{array}{l}\text { Central venous } \mathrm{O}_{2} \text { saturation } \\
\left(\mathrm{SCVO}_{2}\right)\end{array}$ & $64 \%$ & $48-85$ \\
\hline CAM score & 3 & $1-4$ \\
\hline Histidine Rich Protein 2 (HRP2) & $6.1 \mu \mathrm{g} / \mathrm{mL}$ & $1.2-34.6$ \\
\hline
\end{tabular}

* The limit of detection using the IStat system.

haemodialysis). Seven patients received inotropic support (dopamine), although in five of these this was in the pre-terminal setting.

\section{CVP and GEDI}

The median (range) CVP on admission to the study was 5 (-7 to 13) $\mathrm{cmH}_{2} \mathrm{O}$. There was neither an association between admission CVP and disease severity $(\mathrm{p}=0.33)$, nor between admission CVP and patient outcome (5 (-7 to 13) $\mathrm{cmH}_{2} \mathrm{O}$ in survivors versus 6 (-3 to 9) $\mathrm{cmH}_{2} \mathrm{O}$ in those who died, $\mathrm{p}=0.67)$. There was no association between admission CVP and serum creatinine ( $\mathrm{p}=$ $0.57)$, blood urea nitrogen $(\mathrm{p}=0.40)$, venous lactate $(\mathrm{p}$ $=0.34)$ or base deficit $(\mathrm{p}=0.58)$. Admission CVP was higher in patients requiring respiratory assistance during admission (7 (-3 to 9) $\mathrm{cmH}_{2} \mathrm{O}$ versus 2 ( -7 to 13 ) $\mathrm{cmH}_{2} \mathrm{O}$ ), but this did not reach statistical significance ( $\mathrm{p}$ $=0.06$ ) and there was a large overlap between patients who did and did not require this supportive treatment. 
Admission CVP in patients was also higher in patients requiring dialysis later during admission (7 (4 to 9) $\mathrm{cmH}_{2} \mathrm{O}$ versus 3 (-7 to 13$) \mathrm{cmH}_{2} \mathrm{O}$ ). Once again this did not reach statistical significance $(\mathrm{p}=0.08)$ and there was a large overlap between the two groups.

All patients were hypovolaemic with a median (range) GEDI on admission of 481 (346 to 675 ) $\mathrm{ml} / \mathrm{m}^{2}$ (normal $>680 \mathrm{ml} / \mathrm{m}^{2}$ ). There was a correlation between admission GEDI and EVLW ( $\mathrm{p}=0.01)$, but not between admission GEDI and CI $(p=0.35)$. There was no relationship between admission GEDI and mortality (median (range) 467 (346 to 675) in survivors versus 577 (433 to 671) in fatal cases; $p=0.09$ ). There was no correlation between admission GEDI and the base deficit ( $p$ $=0.29)$ or CAM score $(p=0.30)$. There was no relationship between admission GEDI and serum creatinine or blood urea ( $p=0.98$ for both). There was also no relationship between admission GEDI and the later need for RRT $(\mathrm{p}=0.36)$ or respiratory assistance $(\mathrm{p}=0.11)$. There was correlation between admission GEDI and serum lactate $(p=0.05)$, but lower serum lactate levels were seen in patients with a lower GEDI. Notably, there was no correlation on admission between the admission CVP and the GEDI $(\mathrm{p}=0.88)$, the CI $(\mathrm{p}=0.44)$ or the EVLW ( $\mathrm{p}=0.62)$ (Figure 1).

\section{Volume responsiveness}

As the GEDI was used to guide resuscitation, the correlation between admission GEDI and volume of fluid administered was expected $\left(\mathrm{r}_{\mathrm{s}}=-0.55, \mathrm{p}=0.004\right)$. There

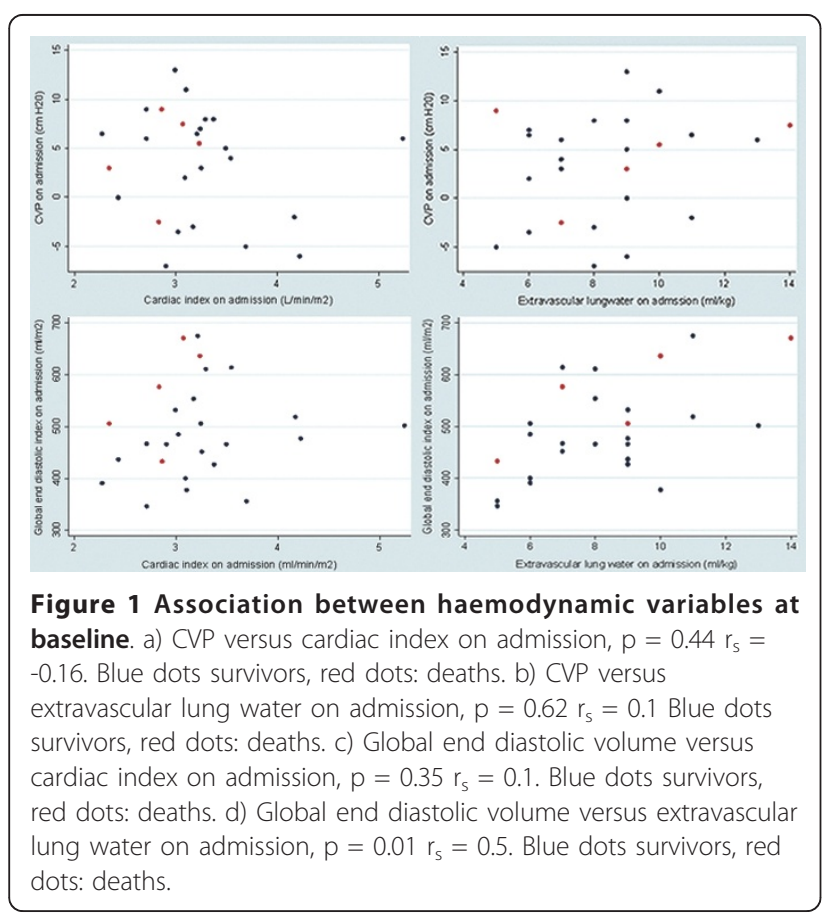

was no relationship between the CVP on admission and the volume of fluid required to resuscitate the patient $\left(\mathrm{r}_{\mathrm{s}}=-0.14, \mathrm{p}=0.47\right)$.

The change in GEDI ( $\triangle$ GEDI) with six hours of fluid loading was correlated with the change in $\mathrm{CI}(\Delta \mathrm{CI})(\mathrm{p}=$ $\left.0.004, r_{s}=0.58\right)$, but there was no correlation between change in CVP $(\triangle \mathrm{CVP})$ and $\Delta \mathrm{CI}\left(\mathrm{p}=0.24, \mathrm{r}_{\mathrm{s}}=0.26\right)$. Of the 28 patients, 12 were fluid responsive (> 15\% increase in CI over $6 \mathrm{~h}$ of fluid loading). Neither the baseline CVP ( $p=0.37)$ or baseline GEDI $(p=0.07)$ predicted whether the patient would be fluid responsive. There was borderline correlation between $\triangle$ GEDI and the change in EVLW ( $\triangle E$ VLW, $\left.\mathrm{p}=0.06, \mathrm{r}_{\mathrm{s}}=0.39\right)$. There was a correlation between $\triangle \mathrm{CVP}$ and $\triangle \mathrm{EVLW}(\mathrm{p}$ $\left.=0.01, \mathrm{r}_{\mathrm{s}}=0.54\right)$, however there was a large overlap in values: a change in EVLW of $1 \mathrm{ml} / \mathrm{kg}$ was associated with a change in CVP of anywhere from -1 to $16 \mathrm{~cm}$ $\mathrm{H}_{2} \mathrm{O}$ (Figure 2).

\section{Correlations with the WHO target range}

The patients had a median (interquartile range (IQR)) of 15 (11 to 18) CVP measurements taken over 96 hours. A median of $17 \%$ (6 to 39 ) of CVP measurements for each patient fell in the WHO recommended range of 0 to $5 \mathrm{cmH}_{2} \mathrm{O}$. Twenty-three $(78 \%)$ of the patients had at least one CVP measurement in the range of 0 to 5 $\mathrm{cmH}_{2} \mathrm{O}$. Twenty of these 23 patients had either hypovolaemia (GEDI < 680), pulmonary oedema (EVLW > 10) or both, at all timepoints when their CVP readings were in this target range. The remaining three patients had

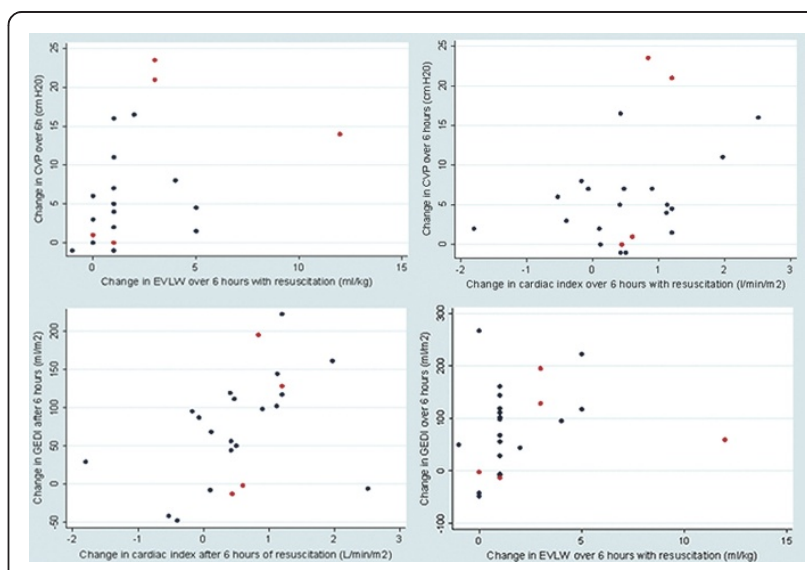

Figure 2 Association between change in haemodynamic variables with fluid loading. a) $\triangle C V P$ versus $\Delta$ cardiac index after 6 hours of fluid resuscitation, $p=0.24 r_{s}=0.26$. Blue dots survivors, red dots: deaths. b) $\triangle C V P$ versus $\triangle$ extravascular lung water after 6 hours of fluid resuscitation, $p=0.005 r_{s}=0.54$. Blue dots survivors, red dots: deaths. c) $\triangle G E D I$ versus $\Delta$ cardiac index water after 6 hours of fluid resuscitation, $p=0.004 r_{s}=0.58$. Blue dots survivors, red dots: deaths. d) $\triangle G E D I$ versus $\Delta$ extravascular lung water after 6 hours of fluid resuscitation, $p=0.056 r_{s}=0.39$. Blue dots survivors, red dots: deaths. 
PiCCO-defined hypovolaemia or pulmonary oedema at $80 \%$, $80 \%$ and $45 \%$ of timepoints when their CVP was in the target range (table 2).

\section{Correlation with JVP}

The jugular venous pressure and central venous pressure were measured simultaneously on 368 occasions. There was a strong correlation between the CVP and JVP $\left(\mathrm{r}_{\mathrm{s}}=0.47, \mathrm{p}<0.001\right)$ however there was no correlation between the JVP and the GEDI $\left(r_{\mathrm{s}}=0.07, \mathrm{p}=\right.$ $0.16), \mathrm{CI}\left(\mathrm{r}_{\mathrm{s}}=0.02, \mathrm{p}=0.69\right)$ or EVLW $\left(\mathrm{r}_{\mathrm{s}}=-0.05, \mathrm{p}=\right.$ $0.32)$.

\section{Complications}

There were significant complications of CVC insertion in $7(25 \%)$ patients, including aspiration of stomach contents during the procedure $(\mathrm{n}=2)$ and blood stream infection $(n=3)$. Persistent oozing of blood around the exit site following insertion necessitated the removal of the CVC in two cases. There was no pneumothorax.
Although there were no fatal complications, all required an escalation of therapy.

\section{Discussion}

The data collected in this study show that in adult patients with severe malaria CVP is not a reliable predictor of volume status, nor is it a clinically useful measure of the likelihood of developing pulmonary oedema, and therefore cannot be used as a guide for fluid therapy. The data collected in this study do not support the WHO recommendation that a CVP of 0-5 $\mathrm{cm} \mathrm{H}_{2} \mathrm{O}$ should be used as a resuscitation target; the vast majority of all patients with a CVP recorded in the target range had concurrent hypovolaemia, pulmonary oedema or both while their CVP was in the target range. There was no correlation between the baseline CVP and the likelihood of the cardiac index (CI) being volume responsive, nor between the change in CVP $(\triangle \mathrm{CVP})$ and change in CI with fluid loading. While $\triangle \mathrm{CVP}$ was correlated with the change in lung water with fluid loading

Table 2 Presence of hypovolaemia or pulmonary oedema whilst CVP in the WHO target range of $0-5 \mathrm{~cm} \mathrm{H}_{2} \mathrm{O}$

\begin{tabular}{|c|c|c|c|c|c|}
\hline $\begin{array}{l}\text { Patient } \\
\text { number }\end{array}$ & $\begin{array}{c}\text { Times CVP in } \\
\text { target range } \\
n\end{array}$ & $\begin{array}{c}\text { No pulmonary oedema*, no } \\
\text { hypovolaemia^ } \\
\text { n (\%) }\end{array}$ & $\begin{array}{c}\text { Pulmonary oedema*, no } \\
\text { hypovolaemia^ } \\
\text { n (\%) }\end{array}$ & $\begin{array}{c}\text { Pulmonary oedema*, } \\
\text { hypovolaemia^ } \\
\text { n (\%) }\end{array}$ & $\begin{array}{c}\text { No pulmonary oedema*, } \\
\text { hypovolaemia^ } \\
\text { n (\%) }\end{array}$ \\
\hline CN10 & 15 & 0 & $2(10)$ & $7(50)$ & $6(40)$ \\
\hline CN14 & 1 & 0 & 0 & 0 & $1(100)$ \\
\hline CN15 & 7 & 0 & 0 & $1(14)$ & $6(86)$ \\
\hline CN18 & 12 & 0 & 0 & 0 & $12(100)$ \\
\hline CN20 & 11 & $6(55)$ & $4(36)$ & 0 & $1(9)$ \\
\hline CN24 & 8 & 0 & 0 & $8(100)^{9}$ & 0 \\
\hline $\mathrm{CN} 25$ & 1 & 0 & 0 & 0 & $1(100)$ \\
\hline CN29 & 1 & 0 & 0 & 0 & $1(100)$ \\
\hline CN30 & 5 & 0 & 0 & 0 & $5(100)$ \\
\hline RN01 & 2 & 0 & 0 & 0 & $2(100)$ \\
\hline RNO3 & 1 & 0 & 0 & 0 & $1(100)$ \\
\hline RN06 & 6 & 0 & 0 & 0 & $6(100)$ \\
\hline RN07 & 1 & 0 & 0 & 0 & $1(100)$ \\
\hline RN08 & 2 & 0 & 0 & 0 & $2(100)$ \\
\hline RN09 & 1 & 0 & 0 & 1(100) & 0 \\
\hline RN10 & 2 & 0 & 0 & 0 & $2(100)$ \\
\hline RN11 & 5 & $1(20)$ & 0 & 0 & $4(80)$ \\
\hline RN12 & 3 & 0 & 0 & 0 & $3(100)$ \\
\hline RN13 & 5 & 0 & 0 & 0 & $5(100)$ \\
\hline RN14 & 7 & 0 & $1(14)$ & $1(14)$ & $5(72)$ \\
\hline RN17 & 1 & 0 & 0 & 1(100) & 0 \\
\hline RN18 & 5 & $1(20)$ & $3(60)$ & 0 & $1(20)$ \\
\hline RN19 & 2 & 0 & 0 & 0 & $2(100)$ \\
\hline
\end{tabular}

'WHO target CVP: 0-5 cm H $\mathrm{H}_{2} \mathrm{O}$

*Pulmonary oedema:EVLW $>10 \mathrm{ml} / \mathrm{kg}$

$\wedge$ Hypovolaemia: GEDI $<680 \mathrm{ml} / \mathrm{m}^{2}$

"This patient had aspiration pneumonia, confounding this measurement. 
there was such a large overlap in values that CVP is rendered clinically useless as a predictor in this situation. There was no correlation between CVP and renal function.

There is no literature on the use of CVP as a resuscitation target in patients with severe malaria, however pulmonary oedema has been shown not to be correlated with either elevated CVP or pulmonary artery occlusion pressure in previous studies of this group of patients $[21,22]$. In the only large study to examine their relationship, measurements of CVP were actually lower in patients with pulmonary oedema than those in patients without this complication [23].

In recent years, there has been a reduction in the emphasis on pressure-based measures as endpoints for resuscitation in critically ill patients [24-27]. CVP is not a good predictor of fluid responsiveness in either healthy volunteers [24] or hypovolaemic critically ill patients [26], and current opinion in well equipped intensive care units is that CVP measurement alone should not be used to define the state of ventricular filling (preload) or the potential of patients to respond to a fluid challenge $[15,16]$.

Adherence to the bundle of care recommended in the Surviving Sepsis Guidelines has been shown to improve the outcomes of patients suffering from severe sepsis. Fluid resuscitation to a CVP of $\geq 8 \mathrm{mmHg}$ in patients with persistent hypotension is one of the key tenets of these guidelines. However, when different components of the bundle of care are independently assessed investigators have shown that there was no association between achieving this CVP target and outcome $[28,29]$. This has led some authors to question the appropriateness of a CVP target in guidelines [30].

Insertion of CVCs is not without risks: mechanical complications occur in 5-19\% of patients, infectious complications occur in 5-26\%, and thrombotic complications occur in 2-26\% [14]. Patients with severe malaria have thrombocytopenia and sometimes coagulopathy increasing the risk of haemorrhage. CVCs are relatively expensive, require medical and nursing expertise to insert and maintain and supporting radiology and microbiology services; all of which will often be lacking in the resource-poor settings where most patients with severe malaria are managed. In our series $25 \%$ of the patients had a significant complication of CVC insertion - a relatively high figure, but indicative of the resource-poor setting in which the patients were managed.

Central venous access for inotrope therapy is needed in only a minority of patients, since shock is a rare complication in severe malaria [1]. Also, parenteral feeding in patients with coma is seldom indicated, since coma recovery is generally within 72 hours [1].
In our study the JVP was strongly correlated with CVP, a relationship that has been noted in other studies $[8,31]$ although the fact that in this study the JVP and CVP were measured by the same examiners concurrently potentially confounds this observation. However, there was similarly little correlation between the JVP and measures of volume status, pulmonary oedema or cardiac index or volume responsiveness. Furthermore JVP is a notoriously challenging sign to interpret, considerable variation exists in expertise in the assessment of JVP, and some studies have shown poor reliability of such assessments in critically ill patients [32,33].

Ultimately, the goal of fluid therapy with the optimization of blood volume is to improve cardiac output and hence oxygen delivery to tissues. However the central pathophysiological mechanism of severe falciparum malaria is the disturbance of microcirculatory blood flow. The adherence of parasitized red blood cells to the endothelium - compounded by auto-agglutination, rosetting and reduced deformability of the red cells - leads to decreased tissue perfusion and the lactic acidosis which has repeatedly been shown to be the strongest predictor of mortality. Microvascular measures like the proportion of obstructed capillaries in rectal mucosa or estimates of the sequestered parasite biomass, have been shown to be strongly correlated with lactic acidosis and outcome in patients with severe malaria $[34,35]$. Fluid loading to systemic haemodynamic targets may do little to overcome this microcirculatory obstruction whereas pulmonary oedema associated with fluid loading in malaria is common and has a mortality rate in adults in resource-poor settings of up to $80 \%[13]$. Recent data collected in African children with severe malaria have demonstrated increased mortality in children treated with aggressive fluid loading [36].

PiCCO derived volume based measures were more reliable as predictors of fluid responsiveness in this group of patients, as has been reported previously [37-40] However, the required expertise and resources limit its feasibility for deployment in the field. Moreover management of critically ill patients using PiCCO based measures has not yet been shown to improve outcome when compared to pressure based systems [41].

There are some important limits to the study. Only a small number of patients were enrolled and PiCCO derived measures were used as our gold standard measure of CI, GEDI and EVLW. The PiCCO system has not been validated in patients with severe malaria; it is theoretically possible that the microcirculatory derangement seen in malaria might affect the Stewart-Hamilton algorithm. The correlation seen between PiCCO measures may be argued to be the result of mathematical coupling although previous research has suggested that this is not the case [42]. The study's findings do not 
preclude the possible utility of central venous access in some patients with severe malaria: central venous access would have value in patients requiring inotropic support or in whom peripheral access is not possible.

In summary, the data collected in this study show that invasive CVP measurement in adult patients with severe malaria provides little clinically useful information, while carrying appreciable morbidity and significant costs relevant to the resource-poor setting in which most patients are managed. In light of these data the WHO recommendations for the routine use of central venous lines and a target CVP of 0-5 $\mathrm{cm} \mathrm{H}_{2} \mathrm{O}$ - in patients with severe malaria should be reconsidered.

\section{Acknowledgements}

The authors would like to acknowledge David Bihari and Martin Boyle for advice during the preparation and execution of the study and Melissa Dalzell for assistance with preparation of the figures.

Funding the study was funded by The Wellcome Trust, UK

\section{Author details}

${ }^{1}$ Department of Medicine, Cairns Base Hospital, Queensland, Australia. ${ }^{2}$ Mahidol Oxford Research Unit, Mahidol University, Bangkok, Thailand. ${ }^{3}$ Department of Medicine, Ispat General Hospital, Rourkela, India.

${ }^{4}$ Department of Intensive Care Medicine, Chittagong Medical College Hospital, Chittagong, Bangladesh. ${ }^{5}$ Department of Medicine, Chittagong Medical College Hospital, Chittagong, Bangladesh. ${ }^{6}$ Department of Intensive Care Medicine, Academic Medical Center, University of Amsterdam, Amsterdam, The Netherlands. ${ }^{7}$ Department of Vascular Medicine, Academic Medical Center, University of Amsterdam, Amsterdam, the Netherlands. ${ }^{8}$ Department of Anaesthetics, Cox's Bazar Medical College, Cox's Bazar, Bangladesh. ${ }^{9}$ Nuffield Department of Clinical Medicine, University of Oxford, Oxford, UK.

\section{Authors' contributions}

$\mathrm{JH}$ devised and performed the study, performed the statistical analysis and was the primary author of the manuscript. SWKL and SC performed the study and collected data. SM, SA, MMUH, AK, SM supervised the study. PC assisted with the logistical preparation and implementation of the project. SJL assisted with the statistical analysis. MJS, NPJD and NJW reviewed and revised the manuscript. AMD was the primary supervisor and revised the manuscript. All authors reviewed the manuscript, and read and approved the final version.

\section{Competing interests}

The authors declare that they have no competing interests.

Received: 23 September 2011 Accepted: 14 November 2011

Published: 14 November 2011

\section{References}

1. Dondorp A, Nosten F, Stepniewska K, Day N, White N: Artesunate versus quinine for treatment of severe falciparum malaria: a randomised trial. Lancet 2005, 366(9487):717-725

2. Dellinger RP, Levy MM, Carlet JM, Bion J, Parker MM, Jaeschke R, Reinhart K, Angus DC, Brun-Buisson C, Beale R, et al: Surviving Sepsis Campaign: international guidelines for management of severe sepsis and septic shock: 2008. Crit Care Med 2008, 36(1):296-327.

3. Castellanos-Ortega A, Suberviola B, Garcia-Astudillo LA, Holanda MS, Ortiz F, Llorca J, Delgado-Rodriguez M: Impact of the Surviving Sepsis Campaign protocols on hospital length of stay and mortality in septic shock patients: results of a three-year follow-up quasi-experimental study. Crit Care Med 2010, 38(4):1036-1043.

4. Patel GW, Roderman N, Gehring H, Saad J, Bartek W: Assessing the effect of the Surviving Sepsis Campaign treatment guidelines on clinical outcomes in a community hospital. Ann Pharmacother 2010, 44(11):1733-1738.

5. Organization Wh: In WHO guidelines for the treatment of malaria. Edited by: Organization WH. Geneva: World Health Organization; 2006:.

6. Management of severe malaria: a practical handbook. Geneva: World Health Organization; Second 2000.

7. McGee S, Abernethy WB, Simel DL: The rational clinical examination. Is this patient hypovolemic? JAMA 1999, 281(11):1022-1029.

8. Cook DJ, Simel DL: The Rational Clinical Examination. Does this patient have abnormal central venous pressure? JAMA 1996, 275(8):630-634.

9. Davis TM, Krishna S, Looareesuwan S, Supanaranond W, Pukrittayakamee S, Attatamsoonthorn K, White NJ: Erythrocyte sequestration and anemia in severe falciparum malaria. Analysis of acute changes in venous hematocrit using a simple mathematical model. J Clin Invest 1990, 86(3):793-800.

10. Sitprija $V$, Napathorn $S$, Laorpatanaskul $S$, Suithichaiyakul T, Moollaor $P$, Suwangool P, Sridama V, Thamaree S, Tankeyoon M: Renal and systemic hemodynamics, in falciparum malaria. Am J Nephrol 1996, 16(6):513-519.

11. Malloy JP, Brooks MH, Barry KG: Pathophysiology of acute falciparum malaria. II. Fluid compartmentalization. Am J Med 1967, 43(5):745-750.

12. Hanson J, Lee SJ, Mohanty S, Faiz MA, Anstey NM, Charunwatthana P, Yunus EB, Mishra SK, Tjitra E, Price RN, et al: A simple score to predict the outcome of severe malaria in adults. Clin Infect Dis 2010, 50(5):679-685.

13. Taylor WR, Canon V, White NJ: Pulmonary manifestations of malaria: recognition and management. Treat Respir Med 2006, 5(6):419-428.

14. McGee DC, Gould MK: Preventing complications of central venous catheterization. N Engl J Med 2003, 348(12):1123-1133.

15. Pinsky MR, Teboul JL: Assessment of indices of preload and volume responsiveness. Curr Opin Crit Care 2005, 11(3):235-239.

16. Osman D, Ridel C, Ray P, Monnet X, Anguel N, Richard C, Teboul JL: Cardiac filling pressures are not appropriate to predict hemodynamic response to volume challenge. Crit Care Med 2007, 35(1):64-68.

17. Godje O, Hoke K, Goetz AE, Felbinger TW, Reuter DA, Reichart B, Friedl R, Hannekum A, Pfeiffer UJ: Reliability of a new algorithm for continuous cardiac output determination by pulse-contour analysis during hemodynamic instability. Crit Care Med 2002, 30(1):52-58.

18. Berton C, Cholley B: Equipment review: new techniques for cardiac output measurement-oesophageal Doppler, Fick principle using carbon dioxide, and pulse contour analysis. Crit Care 2002, 6(3):216-221.

19. Kirov MY, K V, Bjertnaes L: Extravascular lung water in sepsis. In Yearbook of Intensive Care and Emergency Medicine. Edited by: V JL. Berlin Heidelberg New York: Springer-Verlag; 2005:449-460.

20. Fresenius MHM: "Monitoring" in "Repetitorium Intensivmedizin Heidelberg; 2006.

21. Charoenpan P, Indraprasit S, Kiatboonsri S, Suvachittanont O, Tanomsup S: Pulmonary edema in severe falciparum malaria. Hemodynamic study and clinicophysiologic correlation. Chest 1990, 97(5):1190-1197.

22. Day NP, Phu NH, Bethell DP, Mai NT, Chau TT, Hien TT, White NJ: The effects of dopamine and adrenaline infusions on acid-base balance and systemic haemodynamics in severe infection. Lancet 1996, 348(9022):219-223.

23. Aursudkij B, Wilairatana P, Vannaphan S, Walsh DS, Gordeux VR, Looareesuwan S: Pulmonary edema in cerebral malaria patients in Thailand. Southeast Asian J Trop Med Public Health 1998, 29(3):541-545.

24. Kumar A, Anel R, Bunnell E, Habet K, Zanotti S, Marshall S, Neumann A, Ali $A$, Cheang $M$, Kavinsky $C$, et al: Pulmonary artery occlusion pressure and central venous pressure fail to predict ventricular filling volume, cardiac performance, or the response to volume infusion in normal subjects. Crit Care Med 2004, 32(3):691-699.

25. Wiener RS, Welch HG: Trends in the use of the pulmonary artery catheter in the United States, 1993-2004. JAMA 2007, 298(4):423-429.

26. Michard F, Teboul JL: Predicting fluid responsiveness in ICU patients: a critical analysis of the evidence. Chest 2002, 121(6):2000-2008.

27. Cheatham ML, Nelson LD, Chang MC, Safcsak K: Right ventricular enddiastolic volume index as a predictor of preload status in patients on positive end-expiratory pressure. Crit Care Med 1998, 26(11):1801-1806.

28. Levy MM, Dellinger RP, Townsend SR, Linde-Zwirble WT, Marshall JC, Bion J, Schorr C, Artigas A, Ramsay G, Beale R, et al: The Surviving Sepsis Campaign: results of an international guideline-based performance improvement program targeting severe sepsis. Crit Care Med 2010, 38(2):367-374. 
29. Ferrer R, Artigas A, Suarez D, Palencia E, Levy MM, Arenzana A, Perez XL, Sirvent JM: Effectiveness of treatments for severe sepsis: a prospective, multicenter, observational study. Am J Respir Crit Care Med 2009, 180(9):861-866.

30. Machado FR, Freitas FG: Controversies of surviving sepsis campaign bundles: should we use them? Shock 2008, , 30 Suppl 1: 34-40.

31. Vinayak AG, Levitt J, Gehlbach B, Pohlman AS, Hall JB, Kress JP: Usefulness of the external jugular vein examination in detecting abnormal central venous pressure in critically ill patients. Arch Intern Med 2006, 166(19):2132-2137.

32. MCGee SR: Physical examination of venous pressure: a critical review. Am Heart J 1998, 136(1):10-18.

33. Connors AF, McCaffree DR, Gray BA: Evaluation of right-heart catheterization in the critically ill patient without acute myocardial infarction. N Engl J Med 1983, 308(5):263-267.

34. Dondorp AM, Ince C, Charunwatthana P, Hanson J, van Kuijen A, Faiz MA, Rahman MR, Hasan M, Bin Yunus E, Ghose A, et al: Direct in vivo assessment of microcirculatory dysfunction in severe falciparum malaria. $J$ Infect Dis 2008, 197(1):79-84.

35. Dondorp AM, Desakorn V, Pongtavornpinyo W, Sahassananda D, Silamut K, Chotivanich K, Newton PN, Pitisuttithum P, Smithyman AM, White NJ, et al: Estimation of the total parasite biomass in acute falciparum malaria from plasma PfHRP2. PLoS Med 2005, 2(8):e204.

36. Maitland K, Kiguli S, Opoka RO, Engoru C, Olupot-Olupot P, Akech SO, Nyeko R, Mtove G, Reyburn H, Lang T, et al: Mortality after fluid bolus in African children with severe infection. N Engl J Med 2011, 364(26):2483-2495.

37. Della Rocca G, Costa GM, Coccia C, Pompei L, Di Marco P, Pietropaoli P: Preload index: pulmonary artery occlusion pressure versus intrathoracic blood volume monitoring during lung transplantation. Anesth Analg 2002, 95(4):835-843, table of contents.

38. Goedje O, Seebauer T, Peyerl M, Pfeiffer UJ, Reichart B: Hemodynamic monitoring by double-indicator dilution technique in patients after orthotopic heart transplantation. Chest 2000, 118(3):775-781.

39. Lichtwarck-Aschoff M, Beale R, Pfeiffer UJ: Central venous pressure, pulmonary artery occlusion pressure, intrathoracic blood volume, and right ventricular end-diastolic volume as indicators of cardiac preload. $J$ Crit Care 1996, 11(4):180-188.

40. Boussat S, Jacques T, Levy B, Laurent E, Gache A, Capellier G, Neidhardt A: Intravascular volume monitoring and extravascular lung water in septic patients with pulmonary edema. Intensive Care Med 2002, 28(6):712-718.

41. Uchino S, Bellomo R, Morimatsu H, Sugihara M, French C, Stephens D, Wendon J, Honore P, Mulder J, Turner A: Pulmonary artery catheter versus pulse contour analysis: a prospective epidemiological study. Crit Care 2006, 10(6):R174.

42. MCLuckie A, Bihari D: Investigating the relationship between intrathoracic blood volume index and cardiac index. Intensive Care Med 2000, 26(9):1376-1378.

doi:10.1186/1475-2875-10-342

Cite this article as: Hanson et al: Central venous catheter use in severe malaria: time to reconsider the World Health Organization guidelines?

Malaria Journal 2011 10:342.

\section{Submit your next manuscript to BioMed Central and take full advantage of:}

- Convenient online submission

- Thorough peer review

- No space constraints or color figure charges

- Immediate publication on acceptance

- Inclusion in PubMed, CAS, Scopus and Google Scholar

- Research which is freely available for redistribution

Submit your manuscript at www.biomedcentral.com/submit
Biomed Central 